\title{
Article
}

\section{Light-Induced Dynamic Holography}

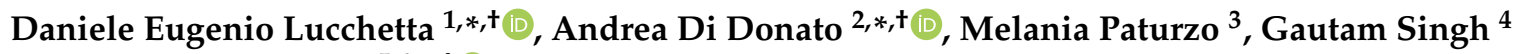 \\ and Riccardo Castagna ${ }^{5,6, *,+}$
}

1 Dipartimento SIMAU, Università Politecnica delle Marche, Via Brecce Bianche, 60131 Ancona, Italy

2 URT-CNR, Università di Camerino (UNICAM), Polo di Chimica, Via Sant'Agostino, 1, 62032 Camerino, Italy

3 CNR ISASI, Via Campi Flegrei 34, 80078 Pozzuoli, Italy; m.paturzo@isasi.cnr.it

4 Department of Applied Physics, Amity Institute of Applied Sciences, Amity University, Uttar Pradesh, Noida 201313, India; gautsingh@gmail.com

5 Dipartimento DII, Università Politecnica delle Marche, Via Brecce Bianche, 60131 Ancona, Italy

6 CNR, Institute of Heritage Science, Via Madonna del Piano, 50019 Sesto Fiorentino, Italy

* Correspondence: d.e.lucchetta@univpm.it (D.E.L.); a.didonato@univpm.it (A.D.D.); riccardo.castagna@cnr.it (R.C.)

+ These authors contributed equally to this work.

check for updates

Citation: Lucchetta, D.E.; Di Donato,

A.; Paturzo, M.; Singh, G.; Castagna,

R. Light-Induced Dynamic

Holography. Micromachines 2022, 13,

297. https://doi.org/10.3390/

mi13020297

Academic Editor: Gregory P. Nordin

Received: 31 December 2021

Accepted: 2 February 2022

Published: 14 February 2022

Publisher's Note: MDPI stays neutral with regard to jurisdictional claims in published maps and institutional affiliations.

Copyright: (C) 2022 by the authors. Licensee MDPI, Basel, Switzerland. This article is an open access article distributed under the terms and conditions of the Creative Commons Attribution (CC BY) license (https:// creativecommons.org/licenses/by/ $4.0 /)$.

\begin{abstract}
Holographic photomobile polymers (H-PMP) are a novel class of photomobile materials in which holograms can be optically recorded. They can be used in a large variety of applications, including optical switches and color selectors. In this work, we show one of the most important properties of the photomobile film, which is the photophobicity of the unpolymerized parts of the photomobile mixture. In order to investigate this property, we recorded a transmission phase grating on an H-PMP film, and used a different experimental technique to measure the diffraction efficiency, surface tension, and mixture properties. The results allowed for a better understanding of the mechanism of the light-controlled bending observed in these compounds
\end{abstract}

Keywords: holography; photomobile polymer; all-optical control; photophobicity

\section{Introduction}

High-resolution transmission and reflection holographic gratings written in polymeric materials are known and investigated for a long time [1,2], and cover a large variety of applications, ranging from high density data storage [3-5], to lasing [6,7], to super-fast holographic displays [8]. More recently, all optically addressable holographic gratings have been also widely studied. They are usually obtained in different ways and show peculiar properties, such as a fast oscillation frequency [9] or the possibility to be integrated into optical circuits as all-optical switches [10-20]. Holographic photomobile polymers (H-PMP) are photomobile materials on which holograms can be optically recorded. The optical characteristics of the recorded hologram can be tuned by using an external pumping light. In this case, the entire film can act as a switch or a color selector [21]. Other applications are possible once the working mechanism is clearly explained. In our previous works, we have focused on the optical and morphological properties of the PMP films; here, we point out our attention on the mobility of the unpolymerized part of the PMP mixture. In previous works, we underlined the possibility of moving the polymer by using a laser beam, due to the conversion of energy to mechanical work [22-25]. Here, the keyword is photophobicity, which is the tendency of the unpolymerized mixture to escape from the light when illuminated [26]. This property is a peculiarity of our PMP film and is directly responsible of its unique mechanical and optical properties. In order to investigate the properties of our materials, we optically recorded a phase transmission grating on a H-PMP film and measured its diffraction efficiency and the surface tension of the unpolymerized part. We also provided suggestions about the material properties and the underlying nature of working mechanism. 


\section{Materials and Methods}

\subsection{Materials}

2,3-bornanedione (CQ), tri-phenyl-o-methane-triglicidyl ether (TPMTGE), dipentaerythritol monohydroxypentaacrylate (DPMHPA), lead (IV) tetra-acetate, para-amino-phenol (4-AP), phenyl-(2,4,6-trimethylbenzoyl) phosphoryl]-(2,4,6-trimethylphenyl) methanone (PTPTM) and N-Vinylbutyrolactam (NVP) came from Sigma Aldrich; lead(IV) oxide $\left(\mathrm{PbO}_{2}\right)$ is freshly prepared by the hydrolysis of lead(IV) acetate.

\subsection{H-PMP Mixture Preparation}

The mixture is prepared starting from the recipe indicated in [26] to which the epoxidemonomer TPMTGE and the photo-initiator 2,3-bornane-dione (CQ) are furthermore added. Chemicals: TPMTGE (0.1 mmol):DPMHPA (1 mmol):NVP (7 mmol):4-AP (1 mmol): $\mathrm{PbO}_{2}$ (0.5 mmol); photo-initiators: CQ $(2 \% w / w), \operatorname{PTPTM~}(2 \% w / w)$. Firstly, a mixture 1 is prepared as follows: DPMPHA is mixed with photoinitiators (CQ and PTPTM) under magnetic stirring at room temperature for $24 \mathrm{~h}$. Then, TPMTGE is added (by heating it at $90{ }^{\circ} \mathrm{C}$, TPMPTGE is in a low viscous form and it can be easily handled). The mixture is left under mechanical stirring until a pale yellow color is obtained. Separately, a mixture 2 is prepared as follows: NVP, 4- $\mathrm{AP}$ and $\mathrm{PbO}_{2}$ are mixed together in aerobic conditions at room temperature in darkness under magnetic stirring for 7 days. After that, the mixture is left at rest at room temperature in darkness for additional 7 days. At this stage, the precipitate formed in the system is carefully removed. The mixture 2 is then filtered to furthermore remove undesired residues of lead oxide. The so obtained mixture 2 is then blended with mixture 1 (the procedure is similar to the one reported in [26]) and the complete final mixture is kept under magnetic stirring for further $36 \mathrm{~h}$ in dark.

\subsection{Experimental Set-Ups}

Our standard cell is made by two microscope glasses separated by two $76 \mu \mathrm{m}$ thick Mylar stripes. The cell is heated at around 60 degrees and the mixture is forced to enter by capillarity. After this, the sample, left for one hour at room temperature on the sample holder, is irradiated by two interfering continuum s-polarized laser beams at $457.9 \mathrm{~nm}$ (see Setup (A) in Figure S1 in Supporting Information Section). During the photo-polymerization, a phase separation process occurs between polymerized and unpolymerized regions of the mixture and, as a result, a one-dimensional (1D) holographic grating is permanently recorded inside the interfering region. This region has a diameter of $5 \mathrm{~mm}$. The used writing power is $150 \mathrm{~mW}$ per beam. A low power $632.8 \mathrm{~nm}$ He-Ne laser positioned at the Bragg diffraction angle is used to detect the grating formation. After three minutes, the grating is completely recorded. To ensure a complete photo-polymerization of the spot area, the total irradiation time is set at $10 \mathrm{~min}$. The sample is post-polymerized for one minute using a U.V. incoherent lamp $(P=0.5 \mathrm{~W}, \lambda=365 \mathrm{~nm})$. The spectral angular analysis of the diffracted wavelengths is performed by illuminating the grating, placed on a motorized goniometer, through a He-Ne laser. Data are acquired for each value of the incident angle (see experimental Setup (B) in Figure S2 in the Supporting Information Section). Finally, a camera provided with a free software (Pendent Drop ImageJ plugin) was used to perform measurements on droplet's surface tension changes of mixture 2 . The same camera was used to detect the droplet's displacement under irradiation.

\section{Theory and Experiments}

The diffraction efficiency of a transmission phase grating is given by the well-known Kogelnik theory [27]. Accordingly, the diffraction efficiency of a one-dimensional transmission phase grating can be written as:

$$
\eta(v, \xi)=e^{-\frac{\alpha d}{\cos \theta}} \frac{\sin \left(\sqrt{\left(v^{2}+\xi^{2}\right)}\right)^{2}}{1+\frac{\xi^{2}}{v^{2}}}
$$


with coupling and detuning parameters, respectively defined as:

$$
\begin{gathered}
v=\frac{\pi \cdot \delta n \cdot d}{\lambda \cdot \cos \theta} \\
\xi=\Delta \theta \cdot \beta \cdot d \cdot \sin \theta_{0}
\end{gathered}
$$

as $\delta n$ is the induced refractive index variation, $d$ the grating thickness, $\lambda$ the reading wavelength in the free space, $\theta$ the angle of incidence, $\theta_{0}$ the Bragg angle, $\alpha$ the distributed absorption coefficient, and $n$ the average refractive index of the medium, and $\beta=2 \pi n / \lambda$.

The parameter $\Delta \theta$ in Equation (3) describes the de-phasing term appearing when $\lambda$ or $\theta$ are varied.

The results obtained from the angular analysis are reported in Figure 1, which shows the diffraction efficiency for the vertical reading polarization as a function of the incidence angle. The two curves represent the diffraction efficiency before and after the post-photopolymerization process. The two continuous lines represent the theoretical data fits obtained by using Equation (1). As we can clearly see, the post-photo-polymerization process reduces the diffraction efficiency of about $30 \%$. The post-polymerization process is indeed needed in order to obtain a useful free standing H-PMP. This phenomenon can be attributed to the photophobic nature of the material, at the basis of the mechanism of the motion of the photomobile polymer film [26]. When a powerful high energy light impinges on the grating, the internal unpolymerized photophobic material tends to escape from the solid polymeric grating. Macroscopically, if continuing to impinge on the system with the same power, the system could partially collapse, due to the thin thickness of the acrylate walls (around $250 \mathrm{~nm} \times 75 \mu \mathrm{m}$ ). The values of optical index contrast reduce, and as a consequence, the diffraction efficiency decreases. Data fit shows an excellent agreement between the theoretical expression reported in Equation (1) and the experimental data and allows the determination of the grating refractive index modulation $\delta n_{1} \sim 2.4 \times 10^{-3}$, $\delta n_{2} \sim 3.4 \times 10^{-3}$, pitch $\Lambda=512.8 \mathrm{~nm}$ and thickness $d=77.98 \mu \mathrm{m}$. Here, $\delta n_{1}$ represents the refractive index modulation before post-photopolymerization, and $\delta n_{2}$ the refractive index after post-photopolymerization. The data have been corrected for angle- and polarizationdependent Fresnel refraction.

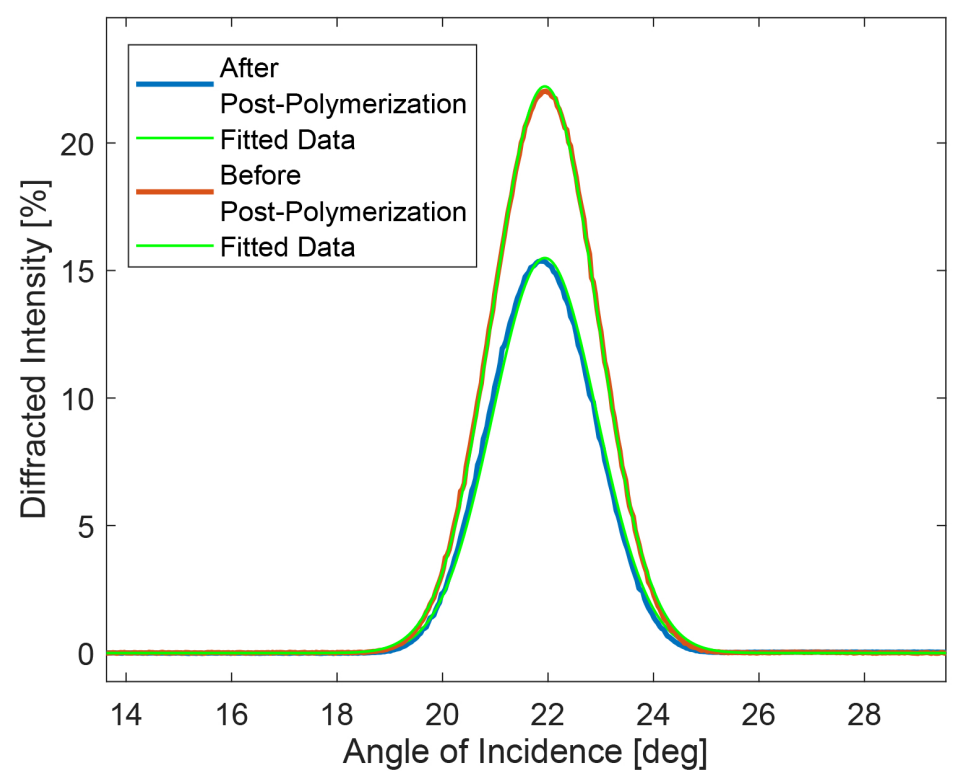

Figure 1. Effects of post-polymerization on the diffraction efficiency of the transmission grating written in the photomobile polymer material. 
Concerning the photophobicity nature of the unpolymerized part of the H-PMP film, we underline how thermal effects play the most important role in the entire process. One of the first experimental observations made on a free pendant small droplet of unpolymerized PMP mixture was indeed its surface tension reduction (due to the increase in temperature), and consequently, its volume increases under laser irradiation (see Figure 2). Figure 2 represents the surface Tension measurements under illumination of a pendent droplet of NVP/4-AP-ox. When illuminating a NVP/4-AP-ox droplet by an unfocused low-power low-coherent laser light $\left(\lambda=405 \mathrm{~nm}\right.$; light density $\left.\approx 0.130 \mathrm{~W} \mathrm{~cm}^{-2}\right)$ its surface tension is almost instantaneously reduced from $\approx 36.3$ to $35.4 \mathrm{mN} \mathrm{m}^{-1}$. Furthermore, we observed the photophobic nature of this material when a laser-light impinged along the vertical direction on a thick droplet placed on a horizontal surface. The droplet escaped rapidly from the irradiated area and returned when irradiation is turned-off. We think that this behavior explains what happens inside the gratings' channels. When the unpolymerized H-PMP mixture escapes along the polymerized channels, the mechanical properties of the film change and a macroscopic bending are observed. At the end of irradiation, the mixture returns inside the channels and the initial condition are restored [21]. Figure 3 is a clear evidence of the mobility of the unpolymerized-PMP-mixture under irradiation.

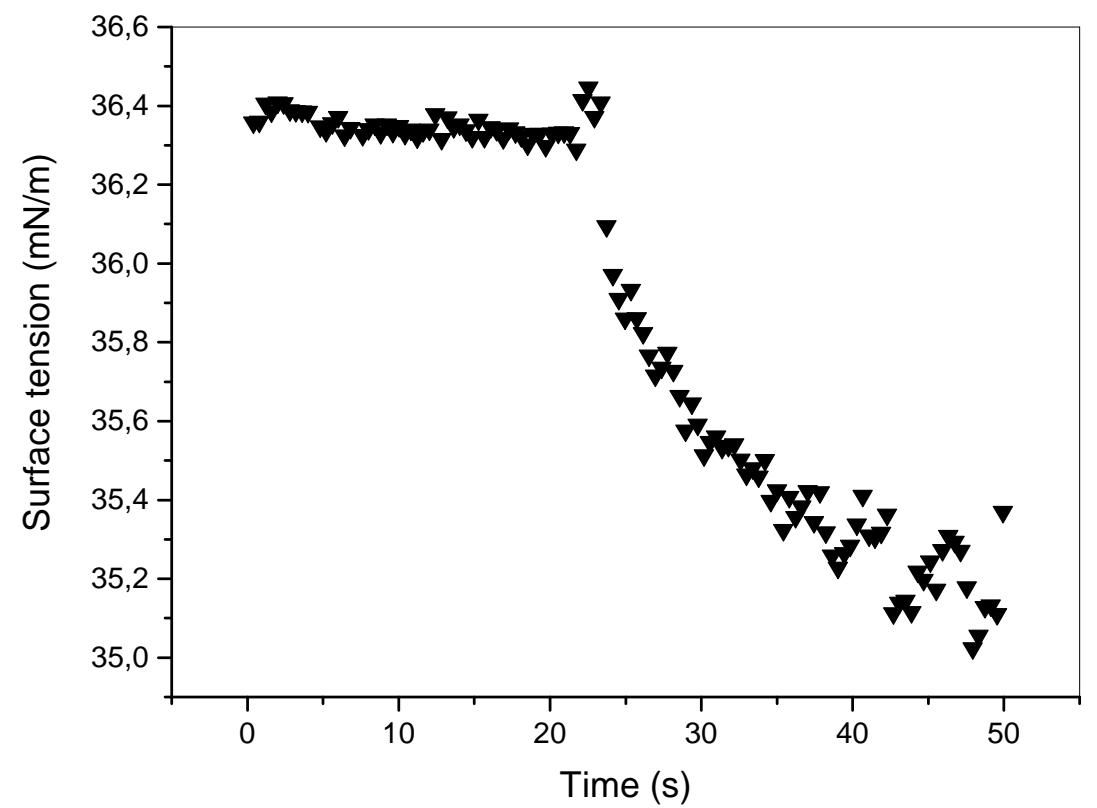

Figure 2. Surface tension as function of time under light irradiation $(\lambda=405 \mathrm{~nm} ; \mathrm{P}=25 \mathrm{~mW})$.

Three experimental observations are here added: (1) the reaction of oxidation of para-amino-phenol by $\mathrm{PbO}_{2}$ could take place even in solid; (2) NVP in presence of $\mathrm{PbO}_{2}$ doesn't seem to react even leaving the suspension of granular 4-AP in NVP for three days, in our experimental conditions. Furthermore, such a suspension does not seem to have any connection with photophobic phenomena; (3) when adding $\mathrm{PbO}_{2}$ to $4-\mathrm{AP}$ in $\mathrm{NVP}$, immediately, the suspension turns on a red dark colored solution and has photophobic properties. Reasonably, amino-phenoxyl-molecule could be generated by hydrogen abstraction on the hydroxyl group of the para-amino-phenol. As a consequence, phenoxyl-radical could be responsible for the further reactivity of 4-AP and NVP, since to the first intitial production of the hydroxyl radical, follows its attack to NVP-vinyl group (see Figure 4), probably bringing possible oligomers of NVP (see FT-IR of Ref. [26]). Furthermore, we cannot exclude a coordination by lead oxide in the system. All these hypotheses are under investigation. This material, however, is actually at the basis of the photophobic nature of the H-PMP evidenced in Figure 3. 

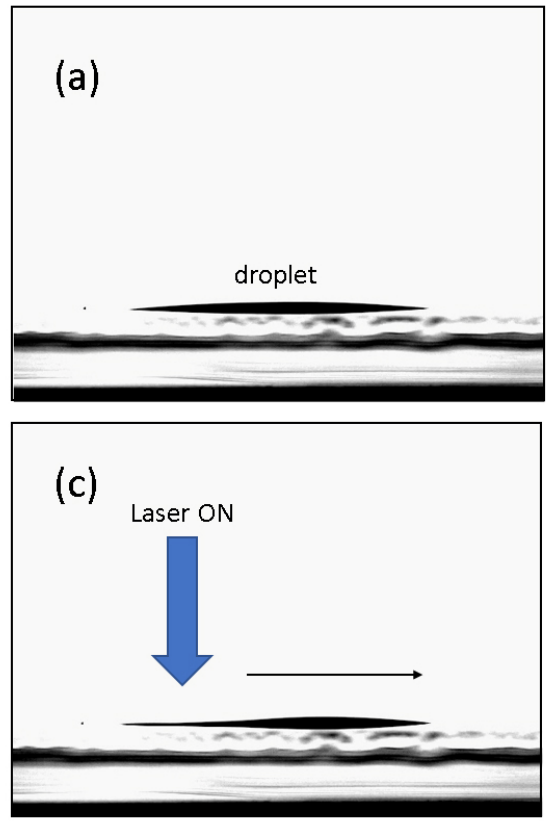

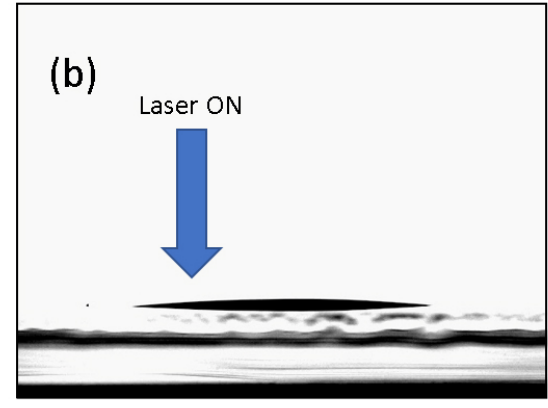

(d) Laser OFF

Figure 3. A droplet of unpolymerized material on a glass surface (a). Under laser irradiation, the droplet tends to escape away from the irradiated area $(\mathbf{b}, \mathbf{c})$. When the laser is switched off, the material returns in its original position $(\mathbf{d})$.

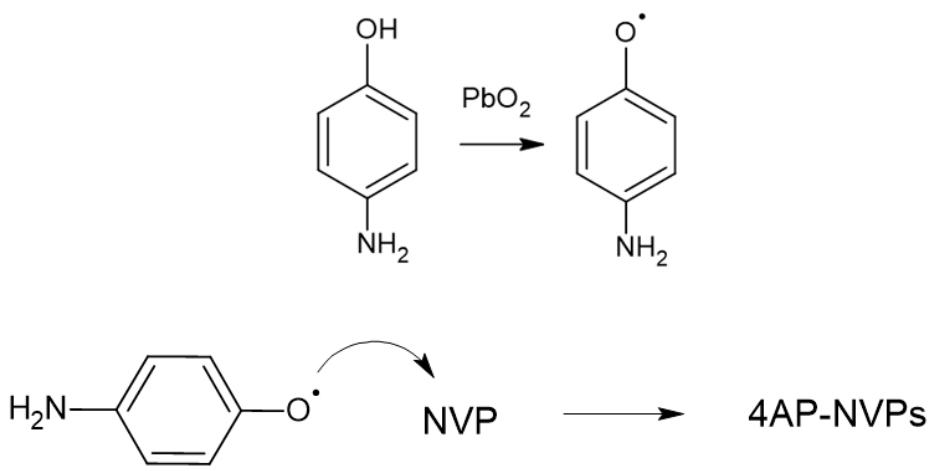

Figure 4. Scheme of the hypothesized reaction mechanism of NVP and 4-AP in oxidative conditions: formation of the phenoxy radical by $\mathrm{PbO}_{2}$ on 4-AP; attack of the phenoxy radical on NVP and oligomer formation.

\section{Conclusions}

In conclusion, we report the angular analysis of one-dimensional holographic transmission phase grating, written on a novel class of photomobile composite polymers: H-PMP material. The experimental data show the presence of a volume phase grating with a pitch $\Lambda=512.8 \mathrm{~nm}$ and a maximum diffraction efficiency of about $22 \%$, at around $22^{\circ}$, which decreases by $30 \%$ after post-polymerization. An explanation of the working mechanism, based on the photophobic nature of the unpolymerized part of the mixture and surface tension changes, is proposed.

Supplementary Materials: The following are available online at https:/ /www.mdpi.com/article/10 .3390/mi13020297/s1. Figure S1: experimental Setup (A), Figure S2: experimental Setup (B).

Author Contributions: Conceptualization, experiments, original draft preparation and data analysis D.E.L., A.D.D., R.C.; supervision, G.S., M.P.; funding acquisition, M.P., R.C. All authors have read and agreed to the published version of the manuscript.

Funding: This research received no external funding. 
Institutional Review Board Statement: Not applicable.

Informed Consent Statement: Not applicable.

Data Availability Statement: Data are available from the authors.

Acknowledgments: The authors thank Luca Nucara from Delta TEch s.r.l. for his help with surface tension measurements. R.C. thanks Progetto MARLIC-Marche Applied Research Laboratory for Innovative Composites (POR Marche FESR 2014/2020) and Project FIRB-MIUR RBPR05JH2P ITALNANONET 2009-2013.

Conflicts of Interest: The authors declare no conflict of interest.

\section{References}

1. Bunning, T.J.; Natarajan, L.V.; Tondiglia, V.P.; Sutherland, R.L. Holographic Polymer-Dispersed Liquid Crystals (H-PDLCs). Ann. Rev. Mater. Sci. 2000, 30, 83-115. [CrossRef]

2. Vita, F.; Lucchetta, D.; Castagna, R.; Francescangeli, O.; Criante, L.; Simoni, F. Detailed investigation of high-resolution reflection gratings through angular-selectivity measurements. J. Opt. Soc. Am. B Opt. Phys. 2007, 24, 471-476. [CrossRef]

3. Castagna, R.; Lucchetta, D.; Vita, F.; Criante, L.; Greci, L.; Simoni, F. Haloalkane-based polymeric mixtures for high density optical data storage. Opt. Mater. 2008, 30, 1878-1882. [CrossRef]

4. Criante, L.; Beev, K.; Lucchetta, D.; Simoni, F. Spectral analysis of shrinkage in holographic materials suitable for optical storage applications. In Holography 2005: International Conference on Holography, Optical Recording, and Processing of Information; International Society for Optics and Photonics: Bellingham, WA, USA , 2006; Volume 6252. [CrossRef]

5. Gao, H.Y.; Liu, P.; Zeng, C.; Yao, Q.X.; Zheng, Z.; Liu, J.; Zheng, H.; Yu, Y.J.; Zeng, Z.X.; Sun, T. Holographic storage of three-dimensional image and data using photopolymer and polymer dispersed liquid crystal films. Chin. Phys. B 2016, $25,094205$. [CrossRef]

6. Lucchetta, D.; Vita, F.; Castagna, R.; Francescangeli, O.; Simoni, F. Laser emission based on first order reflection by novel composite polymeric gratings. Photonics Nanostruct. Fundam. Appl. 2012, 10, 140-145. [CrossRef]

7. Simoni, F.; Bonfadini, S.; Spegni, P.; Turco, S.L.; Lucchetta, D.; Criante, L. Low threshold Fabry-Perot optofluidic resonator fabricated by femtosecond laser micromachining. Opt. Express 2016, 24, 17416-17423. [CrossRef]

8. Gao, H.; Dai, Z.; Liu, J.; Li, S.; Zhou, W.; Xu, F.; Fang, H.; Cheng, X.; Yu, Y.; Zheng, H. Super-fast refresh holographic display based on liquid crystal Films Doped with Silver Nanoparticles. IEEE Photonics J. 2019, 11, 6901107. [CrossRef]

9. White, T.J.; Tabiryan, N.V.; Serak, S.V.; Hrozhyk, U.A.; Tondiglia, V.P.; Koerner, H.; Vaia, R.A.; Bunning, T.J. A high frequency photodriven polymer oscillator. Soft Matter 2008, 4, 1796-1798. [CrossRef]

10. Chang, W.T.; Cheng, C.L.; Li, Y.J.; Wang, T.H.; Kuo, M.Y.; Hsiao, V.K. All-optical switching in holographic polymer dispersed azobenzene liquid-crystal gratings. In Practical Holography XXIII: Materials and Applications; International Society for Optics and Photonics: Bellingham, WA, USA, 2009; Volume 7233, p. 72330X.

11. De Sio, L.; Veltri, A.; Umeton, C.; Serak, S.; Tabiryan, N. All-optical switching of holographic gratings made of polymer-liquidcrystal-polymer slices containing azo-compounds. Appl. Phys. Lett. 2008, 93, 181115. [CrossRef]

12. Su, Y.C.; Chu, C.C.; Chang, W.T.; Hsiao, V. Characterization of optically switchable holographic polymer-dispersed liquid crystal transmission gratings. Opt. Mater. 2011, 34, 251-255. [CrossRef]

13. De Sio, L.; Umeton, C.; Serak, S.; Tabiryan, N. Full Optical Control of Holographic Gratings Realized in Composite Materials Containing Photosensitive Liquid Crystals. Mol. Cryst. Liq. Cryst. 2010, 526, 101-107. [CrossRef]

14. De Sio, L.; Cuennet, J.G.; Vasdekis, A.E.; Psaltis, D. All-optical switching in an optofluidic polydimethylsiloxane: Liquid crystal grating defined by cast-molding. Appl. Phys. Lett. 2010, 96, 131112. [CrossRef]

15. Tong, X.; Wang, G.; Yavrian, A.; Galstian, T.; Zhao, Y. Dual-Mode Switching of Diffraction Gratings Based on AzobenzenePolymer-Stabilized Liquid Crystals. Adv. Mater. 2005, 17, 370-374. [CrossRef]

16. Bang, C.U.; Shishido, A.; Ikeda, T. Azobenzene Liquid-Crystalline Polymer for Optical Switching of Grating Waveguide Couplers with a Flat Surface. Macromol. Rapid Commun. 2007, 28, 1040-1044. [CrossRef]

17. De Sio, L.; Serak, S.; Tabiryan, N.; Ferjani, S.; Veltri, A.; Umeton, C. Composite Holographic Gratings Containing Light-Responsive Liquid Crystals for Visible Bichromatic Switching. Adv. Mater. 2010, 22, 2316-2319. [CrossRef]

18. Lucchetta, D.; Vita, F.; Simoni, F. All-optical switching of diffraction gratings infiltrated with dye-doped liquid crystals. Appl. Phys. Lett. 2010, 97, 231112. [CrossRef]

19. Castagna, R.; Lucchetta, D.E.; Rippa, M.; Xu, J.H.; Di Donato, A. Near-frequency photons Y-splitter. Appl. Mater. Today 2020, 19, 100636. [CrossRef]

20. Lucchetta, D.; Di Donato, A.; Singh, G.; Tombesi, A.; Castagna, R. Optically tunable diffraction efficiency by photo-mobile holographic composite polymer material. Opt. Mater. 2021, 121, 111612. [CrossRef]

21. Castagna, R.; Di Donato, A.; Strangi, G.; Lucchetta, D.E. Light controlled bending of a holographic transmission phase grating. Smart Mater. Struct. 2022, 31, 3. [CrossRef]

22. Lucchetta, D.; Simoni, F.; Sheremet, N.; Reshetnyak, V.; Castagna, R. Shape-driven optofluidic rotational actuation. Eur. Phys. J. Plus 2021, 136, 445. [CrossRef] 
23. Lucchetta, D.; Castagna, R.; Simoni, F. Light-actuated contactless macro motors exploiting Bénard-Marangoni convection. Opt. Express 2019, 27, 13574-13580. [CrossRef] [PubMed]

24. Lucchetta, D.; Simoni, F.; Nucara, L.; Castagna, R. Controlled-motion of floating macro-objects induced by light. AIP Adv. 2015, 5, 077147. [CrossRef]

25. Lucchetta, D.; Simoni, F.; Nucara, L.; Castagna, R. Light moves macro-objects. Prog. Electr. Res. Symp. 2015, $2015,1486-1488$.

26. Castagna, R.; Nucara, L.; Simoni, F.; Greci, L.; Rippa, M.; Petti, L.; Lucchetta, D.E. An Unconventional Approach to Photomobile Composite Polymer Films. Adv. Mater. 2017, 29, 1604800. [CrossRef] [PubMed]

27. Kogelnik, H. Coupled wave theory for thick hologram gratings. In Landmark Papers on Photorefractive Nonlinear Optics; World Scientific: Singapore, 1995; pp. 133-171. 